Article

\title{
Cytokines TNF $\alpha$, IFN $\gamma$ and IL-2 Are Responsible for Signal Transmission from the Innate Immunity Protein Tag7 (PGLYRP1) to Cytotoxic Effector Lymphocytes
}

\author{
Tatiana N. Sharapova *(D), Elena A. Romanova, Olga K. Ivanova, Lidia P. Sashchenko and \\ Denis V. Yashin \\ Laboratory of Molecular Immunogenetics of Cancer, Institute of Gene Biology RAS, Vavilova 34/5, \\ 111394 Moscow, Russia; elrom4@rambler.ru (E.A.R.); olga.k.ivanova@gmail.com (O.K.I.); \\ sashchenko@genebiology.ru (L.P.S.); yashin_co@mail.ru (D.V.Y.) \\ * Correspondence: sharapovatat.nik@gmail.com
}

Received: 3 November 2020; Accepted: 2 December 2020; Published: 4 December 2020

\begin{abstract}
Studies on the mechanisms of activation of cytotoxic lymphocyte subpopulations are an important research direction in modern immunology. This study provides a detailed analysis of the effect of Tag7 (PGRP-S, PGLYRP1) on the development of lymphocyte subpopulations cytotoxic against MHC-negative tumor cells in a pool of peripheral blood mononuclear cells (PBMCs). The results show that Tag7 can bind to the TREM-1 receptor on the surfaces of monocytes, thereby triggering the expression of mRNA TNF $\alpha$ and IFN $\gamma$. The appearance of these cytokines in conditioned medium leads to IL-2 cytokine secretion by $\mathrm{CD}^{+} \mathrm{CD}^{+}$lymphocytes. In turn, IL-2 facilitates unspecific activation of three cytotoxic cell subpopulations in the PBMC pool: $\mathrm{NK}\left(\mathrm{CD} 16^{+} \mathrm{CD} 56^{+}\right), \mathrm{CD}^{+} \mathrm{CD} 4^{+}$ and $\mathrm{CD}^{+} \mathrm{CD}^{+}$. These subpopulations appear after a certain period of incubation with Tag7 and show toxicity against tumor cells.
\end{abstract}

Keywords: PGLYRP1; cancer immunology; monocytes; TREM-1; cytokines; programmed cell death

\section{Introduction}

One of the main goals in molecular immunology is to understand the mechanisms of functioning of the human immune system. Studies on proteins involved in immune activity allow for deeper insight into how this system normally operates in healthy individuals and what factors are responsible for its disturbances characteristic of various pathological states. These studies also contribute to the development of novel means of immune therapy. The cooperative action of innate and adaptive immunity provides for defense against alien agents, and cells involved in the innate and adaptive immune response are stimulated by specific factors. These factors include the family of peptidoglycan recognition proteins (PGRPs) encoded by evolutionarily conserved genes. One of them is the Tag7 (PGLYRP1) protein, which is structurally conserved from insects to mammals [1]. Tag7 in insects is a component of the antimicrobial defense system, which is involved in signal transmission to the TLR4 receptor and thereby activates the production of antimicrobial peptides [2]. Mammalian Tag7 also contributes to antimicrobial defense, but the mechanism of this process has not yet been elucidated in detail [3].

According to our recent data, Tag7 is involved in the immune response against tumor cells. In particular, it can form an equimolar complex with heat shock protein Hsp70 and induce programmed cell death (apoptosis and necroptosis) in tumor cell lines by activating the TNFR1 receptor on the target cell membrane. It has also been shown that the Tag7-Hsp70 complex may be secreted by active 
cytotoxic $\mathrm{CD}^{+}{ }^{+} \mathrm{CD} 8^{+}$lymphocytes [4,5]. Tag7 also plays the role of surface co-receptor on $\mathrm{CD}^{+} \mathrm{CD}^{+}$ and can bind with Hsp70 on MHC-negative tumor cell surfaces. This interaction is critical for FasL-Fas signaling and tumor cell lysis [6].

The role of Tag7 in the elimination of tumor cells is not limited to the direct cytotoxic effect of its complex with Hsp70. It has been shown that Tag7 is capable of binding to the TREM-1 receptor on the monocyte surface and inducing the development of cytotoxic lymphocyte subpopulations in peripheral blood mononuclear cells (PBMCs) [7].

TREM-1 is an innate immunity receptor expressed on monocytes and neutrophils. It is known that this receptor operates synergistically with TLR, enhancing the immune response [8]. TREM-1 activation leads to the secretion of proinflammatory cytokines TNF $\alpha$, IL-1 $\beta$ and IL-6, which activate immune cells [9]. Cytokines play a key role in regulating the immune response against various pathogens stimulating proliferation and maturation of lymphocytes.

$\mathrm{TNF} \alpha$ is one of the best-studied proinflammatory cytokines secreted by innate immunity cells. TNF $\alpha$ binds to two types of transmembrane receptors, TNFR1 and TNFR2. Depending on the receptor type, this binding initiates signaling pathways regulating programmed cell death (apoptosis or necroptosis) and NF-kB activation, which leads to the induction of pro-survival signals [10]. $\mathrm{TNF} \alpha$-signaling in lymphocytes is related to immune modulation [11].

Among other regulators of the immune response, IFN $\gamma$ and IL-2 are important cytokines associated with cytotoxic lymphocytes. Cytokines IFN $\gamma$ and IL-2 stimulate the development of the immune response and support the functioning of effector cells. Thus, IFN $\gamma$-secreted lymphocytes, upon interaction with the target cell, enhance the expression of MHC class 1 in it, which makes such cells readily detectable to $\mathrm{CD} 8^{+}$cytotoxic lymphocytes [12]. IL-2 controls homeostasis and differentiation of $\mathrm{T}$ cells [13]. In particular, it stimulates the proliferation of naive CD8 lymphocytes and their maturation into cytotoxic lymphocytes capable of secreting IFN $\gamma$ and killing infected cells [14]. Long-term incubation of lymphocytes with IL-2 induces their differentiation into LAK cells cytotoxic against tumor cells [14,15].

The purpose of this study was to analyze basic stages in the formation of cytotoxic lymphocyte subpopulations under the effect of Tag7 and the involvement of the aforementioned cytokines in these processes.

\section{Materials and Methods}

\subsection{Cells}

Human peripheral blood mononuclear cells (PBMCs) from healthy donors were isolated by sequential centrifugation in a Ficoll gradient as described [4]. All procedures performed were in accordance with the Declaration of Helsinki (1964) and its later amendments (World Medical Association, 2013) or comparable ethical standards and were approved by the medical ethics committee of FSBI N.N. Blokhin National Medical Research Center of Oncology of the Ministry of Health of the Russian Federation. Purified PBMCs $\left(4 \times 10^{6}\right.$ cells $\left./ \mathrm{mL}\right)$ were incubated in RPMI-1640 with $10 \%$ FCS and antibiotics (penicillin and streptomycin). Human erythroblastoma K562 cells used as targets for cytotoxicity assay were cultured in the same medium. This cell line was obtained from the cell line collection of N. N. Blokhin National Medical Research Center of Oncology of the Ministry of Health of Russia.

\subsection{Magnetic Bead-Based Cell Separation}

Lymphocyte subpopulations were isolated using Dynabeads Untouched kits (Invitrogen, USA) for human CD4, CD8 and NK cells (CD16 $\left.{ }^{+} \mathrm{CD} 56^{+}\right)$and monocytes $\left(\mathrm{CD} 14^{+}\right)$. Antibodies to CD25 and CD132 were coupled to PanMouse IgG beads (Invitrogen, Waltham, MA, USA), and anti-CD122 antibodies were bounded to M-280 Sheep Anti-Rabbit IgG (Invitrogen, Waltham, MA, USA). All procedures were performed as recommended by the manufacturers. 


\subsection{Affinity Chromatography, Immunoadsorption and Western Blotting}

sTREM-1 (AA 1-200, His tag, antibodies-online GmbH, Germany) was conjugated to CNBr-activated Sepharose 4B (GE, Chicago, IL, USA) according to the manufacturer's protocol. The Tag7 was loaded onto the TREM-1-Sepharose 4B column. The column was thoroughly washed with PBS (contained $0.5 \mathrm{M} \mathrm{NaCl}$ ) and PBS alone and then eluted with triethylamine (pH 12, $0.25 \mathrm{M}$ ). The eluted material was resolved by SDS-PAGE and blotted onto a nitrocellulose membrane. To detect Tag7, primary rabbit anti-Tag7 antibodies $(1: 10,000)$ followed by secondary HRP-conjugated anti-rabbit antibody (GE, Chicago, IL, USA; 1:15,000) were used. For visualization purposes, ECL Plus kit (GE, Chicago, IL, USA) was used according to the manufacturer's protocol.

\subsection{Activating Agents}

Lymphocyte activation was induced by Tag7 and IL-2 or IFN $\gamma$ added to a final concentration of $10^{-9}$ M. Recombinant Tag7 (PGLYRP1) was prepared as described [4]. Recombinant IL-2, TNF $\alpha$ and IFN $\gamma$ were from Sigma (St. Louis, MO, USA).

\subsection{Cytotoxicity Assay}

Lymphocyte preparations were mixed with target $\mathrm{K} 562$ cells at a $20: 1$ ratio $\left(1.2 \times 10^{6}\right.$ and $60 \times 10^{3}$ cells, respectively), incubated at $37{ }^{\circ} \mathrm{C}$ in a $5 \% \mathrm{CO}_{2}$ atmosphere for $3 \mathrm{~h}$, and their cytotoxic activity was measured using a CytoTox 96 Assay kit (Promega, Madison, WI, USA) according to the manufacturer's protocol.

\subsection{Antibodies and Inhibitors}

TREM-1 receptor activation was blocked by the inhibitory peptide LP17 (LQVTDSGLYRCVIYHPP, $\left.10^{-9} \mathrm{M}\right)$. Signaling molecules associated with the IL-2R receptor were blocked using specific inhibitors of JAK1 and JAK3 $(5 \mu \mathrm{M})$ and of STAT3 and STAT5 $(10 \mu \mathrm{M})$ (Santa Cruz Biotechnology, Santa Cruz, CA, USA). All inhibitors were added $1 \mathrm{~h}$ before lymphocyte treatment with an activating agent. Inhibitors of STAT3 and STAT5 were additionally added to PBMC on days 3 and 5 of incubation. Rabbit anti-Tag7 antibodies were obtained as described [4]. Mouse anti-human CD25 and rabbit anti-human CD122 antibodies were from Invitrogen (Waltham, MA, USA); mouse anti-human CD132 antibodies were from R\&D (Minneapolis, MN, USA); mouse anti-human IFN $\gamma$, rat anti-human TNF $\alpha$ and rat anti-human IL-2 antibodies were from Invitrogen (Waltham, MA, USA).

\subsection{ELISA}

The levels of secretion of different cytokines were evaluated with Human IL-2, IFN $\gamma$ and TNF $\alpha$ ELISA Kits (Thermo Fisher Scientific, Waltham, MA, USA) according to the manufacturer's protocols.

\section{8. $q P C R$}

RNA was isolated from the fraction of $\mathrm{CD}^{+} \mathrm{CD}^{+}$-lymphocytes (purified by magnetic cell separation) after their treatment with Tag7 $\left(10^{-9} \mathrm{M}\right)$ for 22 and $46 \mathrm{~h}$. A sample of $4 \times 10^{6}$ lymphocytes was lysed in $500 \mu \mathrm{L}$ of Trizol Reagent (Invitrogen, Waltham, MA, USA), incubated at room temperature for $5 \mathrm{~min}$, frozen and stored at $-70{ }^{\circ} \mathrm{C}$. RNA measurement was conducted with NanoDrop (Thermo scientific, USA), and equal amounts of RNA $(1 \mu \mathrm{g})$ were used. For detection, RNA degradation electrophoresis was applied. The synthesis of cDNA was performed with oligo(dT) primers (Eurogen, Waltham, MA, Moscow, Russia). The products were used for qPCR with primers for genes encoding RPLP0, IL-2, $\mathrm{CD} 25, \mathrm{CD} 122, \mathrm{CD} 132$ and IFN $\gamma \cdot \mathrm{CD}^{+} \mathrm{CD}^{+}$-lymphocytes were purified from PBMC by magnetic bead isolation and then activated with TNF $\alpha$ and IFN $\gamma$. The level of RPLP0 mRNA was taken as a reference gene. The primers were as follows. RPLP0 forward: 5' -ACTGGAGACAAAGTGGGAGCC, reverse: 5'-CAGACACTGGCAACATTGCG; IL-2 forward: 5' AAACTCACCAGGATGCTCAC 3', reverse: 5' TGTTTCAGATCCCTTTAGTTCCAG 3'; CD25 forward: 5’ CAGTTTCCAGGTGAAGAGAAGC 3’, 
reverse: 5' CTGTTGTAAATATGGACGTCTCCA 3'; CD122 forward: 5' CCTTTGAGAACCTTCGCCTG $3^{\prime}$, reverse: 5' GGTGTCTTTCAAAGTAGTGGGAG 3'; CD132 forward: 5' GCATTATTGGTACAAGA ACTCGG $3^{\prime}$, reverse: $5^{\prime}$ ACAAATGTTTGGTAGAGGTGGA $3^{\prime}$; IFN $\gamma$ forward: $5^{\prime}$ GGGTTCTC TTGGCTGTTACTG 3'; reverse: $5^{\prime}$ TTCTGTCACTCTCCTCTTTCCA $3^{\prime}$; TNF $\alpha$ forward: $5^{\prime}$-CTTCTCCTT CCTGATCGTGC-3' ; reverse: $5^{\prime}$-GCTGGTTATCTCTCAGCTCCA-3' . Measurements at each point were made with at least three replications, and the mean value was calculated. Expression values were quantified using the equation of fold over control $=2^{\Delta \Delta \mathrm{Ct}}$ method, where $\Delta \mathrm{Ct}$ represents the differences in cycle threshold numbers between the target gene and reference gene, and $\Delta \Delta \mathrm{Ct}$ represents the relative change in these differences between control and treatment groups.

\subsection{Statistical Analysis}

Data are presented as the average \pm standard deviation. All experiments were repeated at least three times. Testing for significant differences between treatment and control was performed with MathCad software (PTC, Cambridge, MA, USA) using the Student $t$ test for experiments on cell treatment with a single agent and 2-way ANOVA for experiments on cell treatment with 2 or more agents (see individual figure legends). $p$-values of less than 0.05 were considered significant.

\section{Results}

3.1. Treatment of PBMCs with Tag7 Results in the Formation of Cytotoxic Subpopulations of NK $\left(C D 16^{+} C D 56^{+}\right), C D 3^{+} C D 4^{+}$and $C D 3^{+} C D 8^{+}$Lymphocytes, But Only If the PBMC Pool Contains Monocytes

As we have previously shown, Tag7 can induce in PBMCs of at least three distinct subpopulations of cytotoxic lymphocytes that alternately exhibit their activity against HLA-negative tumor cell lines during a 6-day incubation period [7]. In this study, Tag7 also proved to induce the cytotoxic fraction of NK cells $\left(\mathrm{CD} 16^{+} \mathrm{CD} 56^{+}\right)$, which reached a peak of activity on day 3-4. The number of these cells subsequently decreased significantly, and cytotoxicity associated with them was no longer observed (Figure S1). The cytotoxic activity of $\mathrm{CD}^{+} \mathrm{CD}^{+}$lymphocytes was detected on days 4 and 6 of incubation with Tag7, while that of $\mathrm{CD}^{+} \mathrm{CD}^{+}$lymphocytes was only detected on day 6 (Figure S1).

According to our previous data, Tag7 treatment of PBMCs depleted of monocytes does not result in the induction of cytotoxic activity [7]. Here, we tested whether monocytes are necessary for the formation of each cytotoxic lymphocyte subpopulation. Monocytes were removed from PBMCs by magnetic cell separation, and the resulting PBMC mc (-) cells were incubated with Tag7. Using the same method, $\mathrm{NK}$ cells and $\mathrm{CD}^{+}{ }^{+} \mathrm{CD} 4^{+}$lymphocytes were isolated from the Tag7-treated PBMC mc $(-)$ cell pool on incubation day 4 , and $\mathrm{CD}^{+} \mathrm{CD}^{+}$lymphocytes were isolated on day 6 . Cytotoxicity tests showed that the removal of monocytes prevented the induction of cytotoxic activity in either NK cells or $\mathrm{CD}^{+} \mathrm{CD}^{+}$and $\mathrm{CD}^{+} \mathrm{CD}^{+}$lymphocytes (Figure 1a). As a control, we also used an inhibitory peptide to TREM-1 receptor LP17, which was added to PBMC $1 \mathrm{~h}$ before activation Tag7. The data demonstrated the absence of the cytotoxic activity of PBMC during 6-day co-incubation of the LP17 peptide and Tag7 (Figure 1a). Thus, monocytes appear to be the first link in the chain of signal transmission from Tag7 to effector lymphocytes.

It is known that Tag7 is a ligand for the innate immune receptor TREM-1 [16]. We continued to study the interaction of Tag7 with TREM-1 by affinity chromatography. We detected the binding of a soluble form of TREM-1 immobilized on Sepharose with Tag7 (Figure 1b). An excess amount of Tag7 was passed through the column with TREM-1 immobilized on CNBr-Sepharose. Elution of Tag7 bound to TREM- 1 was performed using triethylamine, and the material was analyzed by SDS-PAGE and WB. The elution material containing Tag7 was detected with specific antibodies (Figure 1b (1)). Recombinant Tag7 was used as a control for the obtained results, which were analyzed by SDS-PAGE and WB and developed with specific antibodies (Figure $1 b(2)$ ). 


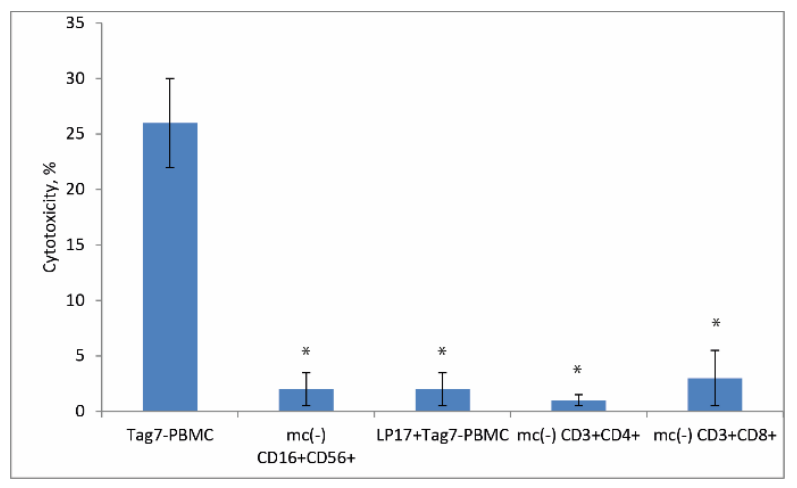

(a)

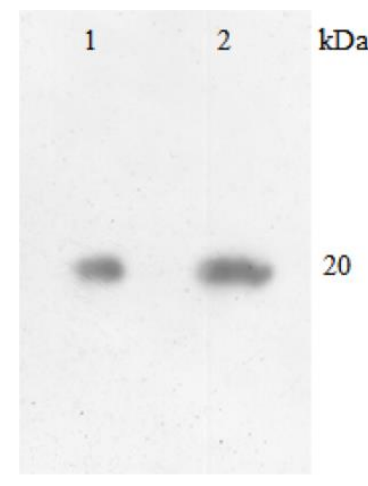

(b)

Figure 1. Monocytes are necessary for the induction of cytotoxic lymphocyte subpopulations by Tag7. (a) PBMCs were depleted of monocytes (mc-) and treated with Tag7 for 4 days (for CD16 ${ }^{+} \mathrm{CD} 56^{+}$cells) or 6 days (for $\mathrm{CD}^{+} \mathrm{CD}^{+}$and $\mathrm{CD} 3^{+} \mathrm{CD} 8^{+}$cells). These lymphocyte subpopulations were isolated by magnetic cell separation and tested for cytotoxicity against K562 cells. The peripheral blood mononuclear cell (PBMC) pool was treated with Tag7 for 6 days in the presence of peptide LP17 (1nM) TREM-1 inhibitor (added $1 \mathrm{~h}$ prior to treatment), and then cytotoxic activity against K562 cells was measured. Data are presented as the mean \pm SD of 3 independent experiments. Error bars represent SD between triplicates. Differences from the control in all cases are significant at ${ }^{*} p<0.05$ (Student $t$ test). (b) Tag7, applied to the TREM-1 conjugated Sepharose column and then eluted and detected by WB (1). WB of Tag7 (20kDa) was used as a control (2). Anti-Tag7 rabbit antibodies, with anti-rabbit antibodies conjugated to peroxidase subsequently, were used for staining.

\subsection{Tag7 Stimulates Secretion of Cytokines TNF $\alpha$, IFN $\gamma$ and IL-2}

Taking into account that monocytes produce lymphocyte-activating factors [17], our next task was to analyze the profile of cytokines secreted to the medium by Tag7-activated PBMCs. First, PBMCs were incubated with Tag7 for 3 days, and samples of the conditioned medium were taken every $24 \mathrm{~h}$ for quantitative determination of proinflammatory cytokines TNF $\alpha$ uIFN $\gamma$ by ELISA. As shown in Figure $2 \mathrm{a}$, the level of TNF $\alpha$ reached a peak on day 2 and then decreased, while the level of IFN $\gamma$ consistently increased during the incubation period. Thus, PBMCs treated with Tag7 secrete not only the proinflammatory cytokine TNF $\alpha$ but also IFN $\gamma$, which is known for its role in antiviral defense and the ability to activate lymphocytes, acting together with IL-2.

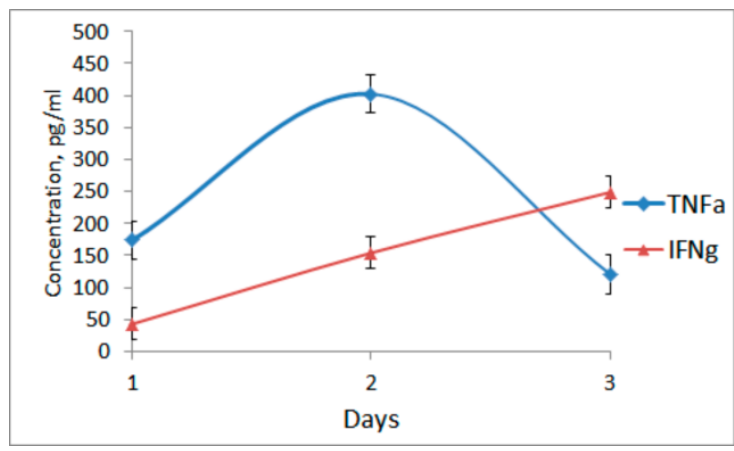

(a)

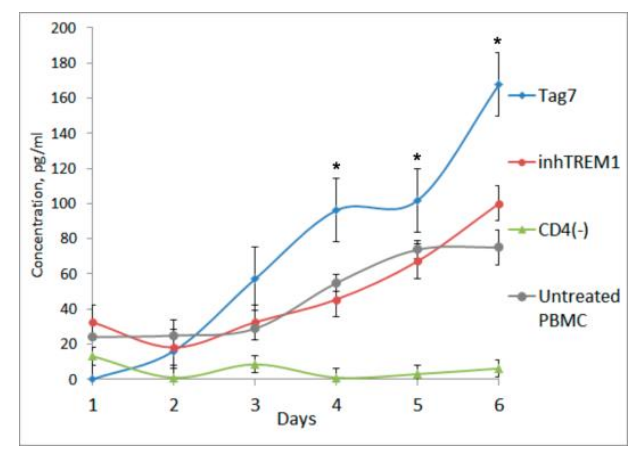

(b)

Figure 2. Secretion of proinflammatory cytokines by PBMCs incubated with Tag7 for 1-6 days. (a) The medium conditioned by Tag7-activated PBMCs was sampled every $24 \mathrm{~h}$ to determine the levels of TNF $\alpha$ and IFN $\gamma$ by ELISA. (b) Secretion of IL-2 by PBMCs incubated with Tag7 for 6 days without additional treatment (Tag7); after blocking TREM-1 receptor on monocytes by inhibitory peptide LP17 
$\left(10^{-9} \mathrm{M}\right)$ added $1 \mathrm{~h}$ before incubation with Tag7 (inhTREM-1) and after preliminary removal of $\mathrm{CD}^{+} \mathrm{CD}^{+}$lymphocytes by magnetic separation (CD4(-)) and conditioned medium without treatment (Untreated PBMC). The medium conditioned by Tag7-activated PBMCs was sampled every $24 \mathrm{~h}$ to determine IL-2 level by ELISA. Data are presented as the mean \pm SD of 3 independent experiments. Differences from the control in all cases are significant at * $p<0.05$ (2-way ANOVA).

We then evaluated the profile of IL-2 secretion by Tag7-activated PBMCs and the involvement of monocytes in its induction. In this case, PBMCs were incubated with Tag7 for 6 days. In view of the data that TREM-1 activation may lead to the induction of genes coding for proinflammatory cytokines $[7,9]$, the incubation was also performed in the presence of specific TREM-1 inhibitor LP17. Conditioned medium from untreated PBMC was used as additional control. The medium conditioned by PBMCs was sampled every $24 \mathrm{~h}$. The results showed that the level of IL-2 consistently increased during the incubation period in both variants but was generally lower when TREM-1 activation was blocked or when untreated PBMC was used (Figure 2b). Despite the presence of a certain amount of IL-2 in conditioned medium, we did not observe cytotoxic activity after 6 days of co-incubation of LP17 and Tag7 with PBMC (Figure 1a). This is evidence that the interaction of Tag7 with TREM-1 is necessary for inducing PBMCs to produce and secrete a sufficient amount of IL-2 into the medium to a mature lymphocytes subpopulation.

\section{3. $C D 3^{+} C D 4^{+}$Lymphocytes Are the Main Source of IL-2 and Are Necessary for the Formation of Each Cytotoxic Subpopulation}

The appearance of TNF $\alpha$ and IFN $\gamma$ in the conditioned medium in the first days of Tag7 incubation with PBMC plays an important role in the formation of an activation signal. We hypothesized that these cytokines promote the activation of $\mathrm{CD}^{+} \mathrm{CD}^{+}$-lymphocytes and the secretion of IL-2. In view of this hypothesis, we then analyzed the changes in the expression of mRNA of IL-2, IFN $\gamma$ and $\mathrm{TNF} \alpha$ in $\mathrm{CD}^{+} \mathrm{CD}^{+}$-lymphocytes under the treatment of $\mathrm{TNF} \alpha$ and IFN $\gamma$. A subpopulation of $\mathrm{CD}^{+} \mathrm{CD}^{+}$-lymphocytes was isolated by magnetic separation from PBMCs and incubated with recombinant TNF $\alpha$ or IFN $\gamma$ for $24 \mathrm{~h}$. As shown in Figure 3a, incubation of $\mathrm{CD}^{+} \mathrm{CD}^{+}$-lymphocytes with recombinant TNF $\alpha$ led to increased levels of IL-2 mRNA (45-fold), IFN $\gamma$ (36-fold) and TNF $\alpha$. Comparable results were detected in $\mathrm{CD}^{+} \mathrm{CD}^{+}$-lymphocytes incubated with IFN $\gamma$. The level of IL-2 mRNA increases greater (more than 97-fold) than IFN $\gamma$ mRNA (15-fold) in the case of incubation of $\mathrm{CD}^{+} \mathrm{CD}^{+}$-lymphocytes with recombinant IFN $\gamma$. In both cases, under the action of $\mathrm{TNF} \alpha$ and IFN $\gamma$ in lymphocytes, there is a slight change in TNF $\alpha$ mRNA expression by $2-4$ folds. To prove the effect of TNF $\alpha$ and IFN $\gamma$ cytokines on the secretion of IL-2 CD3 ${ }^{+} \mathrm{CD}^{+}{ }^{+}$-lymphocytes, we analyzed the conditioned medium of pure $\mathrm{CD}^{+} \mathrm{CD}^{+}$-lymphocytes after TNF $\alpha$ or IFN $\gamma$ treatment. We demonstrated that under TNF $\alpha$ or IFN $\gamma$ treatment, $\mathrm{CD}^{+} \mathrm{CD}^{+}-$lymphocytes secrete IL-2 into conditioned medium (Figure S2). It was also shown that specific antibodies against cytokines TNF $\alpha$, IFN $\gamma$ and IL-2, which were co-incubated with Tag7-PBMC, decrease the cytotoxic effect of Tag7-PBMC against tumor cells (Figure S3).

Thus, we can point out that secretion of TNF $\alpha$ and IFN $\gamma$ after incubation of Tag7 with PBMC in the first days triggers the activation of $\mathrm{CD}^{+} \mathrm{CD}^{+}$-lymphocytes.

Since $\mathrm{CD}^{+} \mathrm{CD}^{+}$-lymphocytes are the main source of IL-2 in the immune response system [18], it was relevant to assess the role of $\mathrm{CD}^{+}{ }^{+} \mathrm{CD} 4^{+}$cells in the transmission of activation signal from Tag7 and the production of IL-2 in the Tag7-PBMC system. Therefore, we evaluated IL-2 secretion in PBMCs depleted of $\mathrm{CD}^{+} \mathrm{CD}^{+}$-lymphocytes by magnetic separation and incubated with Tag7 for 6 days. As shown in Figure 2b, no IL-2 was detected in the conditioned medium. Moreover, PBMCs depleted of $\mathrm{CD}^{+} \mathrm{CD}^{+}$-lymphocytes showed no cytotoxic activity (Figure 3b). It appears that the cytotoxic activity of lymphocytes is stimulated by IL-2 produced by $\mathrm{CD}^{+} \mathrm{CD}^{+}$-cells under the effect of Tag7 and secreted into the medium. 


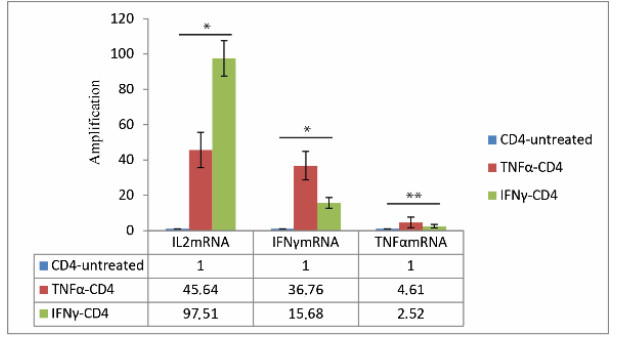

(a)

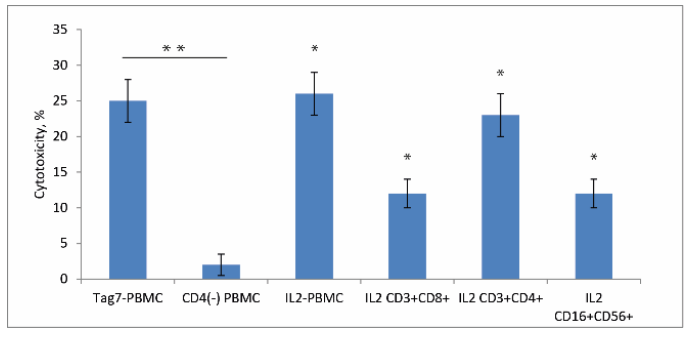

(b)

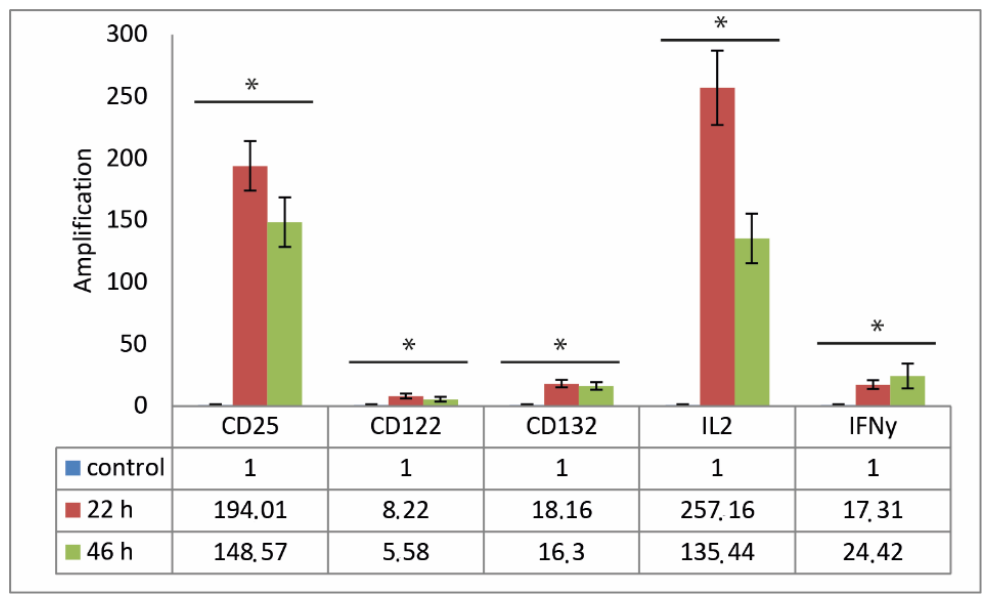

(c)

Figure 3. The role of $\mathrm{CD}^{+} \mathrm{CD}^{+}$-lymphocytes in the activation of effector lymphocytes. (a) Incubation of $\mathrm{CD}^{+} \mathrm{CD}^{+}$-lymphocytes with IL-2, IFN $\gamma$ and TNF $\alpha$ results in activation of genes for IFN $\gamma$ and $\mathrm{TNF} \alpha$ in $\mathrm{CD}^{+} \mathrm{CD}^{+}$-lymphocytes after $24 \mathrm{~h}$. Transcription level was determined by qPCR with RPLP0 mRNA level used as control. The results are presented as fold change in gene expression after treatment with IFN $\gamma$ and TNF $\alpha$ compared to that in control (untreated) $\mathrm{CD}^{+} \mathrm{CD} 4^{+}$-lymphocytes. (b) Cytotoxic activity of lymphocyte subpopulations stimulated by Tag7 and IL-2. PBMCs or individual lymphocyte subpopulations were treated with Tag7 $\left(10^{-9} \mathrm{M}\right)$ or IL-2 $\left(10^{-9} \mathrm{M}\right)$ for 6 days (4 days in the case of $\mathrm{CD} 16^{+} \mathrm{CD} 56^{+}$) and tested for cytotoxicity against K562 cells. (c) Incubation of PBMCs with Tag7 results in activation of genes for IL-2R $\alpha$ (CD25), IL-2R $\beta$ (CD122), IL-2R $\gamma$ (CD132), IL-2 and IFN $\gamma$ BCD3 $^{+}$ $\mathrm{CD}^{+}$-lymphocytes after 22 and $46 \mathrm{~h}$. Transcription level was determined by qPCR with RPLP0 mRNA level used as control. The results are presented as fold change in gene expression after treatment with Tag7, compared to that in control (untreated) lymphocytes. Data are presented as the mean \pm SD of 3 independent experiments. Differences from the control in all cases are significant at ${ }^{*} p<0.05$ and ** $p<0.03$ (2-way ANOVA).

Our next task was to estimate the effect of IL-2 secreted into the medium by Tag7-treated PBMCs on the formation of individual cytotoxic lymphocyte subpopulations. To this end, subpopulations of $\mathrm{NK}\left(\mathrm{CD}_{16}{ }^{+} \mathrm{CD}_{5}{ }^{+}\right), \mathrm{CD}^{+} \mathrm{CD}^{+}$and $\mathrm{CD}^{+} \mathrm{CD}^{+}$cells were isolated from PBMCs by magnetic separation and incubated with recombinant IL-2 for 4 or 6 days. The results showed that all these subpopulations acquired the ability to kill K562 tumor cells after treatment with IL-2. To test whether Tag7 directly induces cytotoxicity in effector cells, the same lymphocyte subpopulations were treated with this protein. No cytotoxic activity was detected in this case, indicating that Tag7 has no direct effect on this activity (Figure $3 b$ ). This is evidence that IL-2 produced by $\mathrm{CD} 3^{+} \mathrm{CD} 4^{+}$lymphocytes plays a key role in inducing the cytotoxic activity of $\mathrm{NK}, \mathrm{CD}^{+} \mathrm{CD}^{+}$and $\mathrm{CD} 3^{+} \mathrm{CD} 8^{+}$cells.

We then analyzed changes in the expression of genes encoding IFN $\gamma$, IL-2 and IL-2 receptor subunits-IL-2R $\alpha$ (CD25), IL-2R $\beta$ (CD122) and IL-2R $\gamma(C D 132)$-in CD3 ${ }^{+}$CD $4^{+}$lymphocytes under the effect of PBMC treatment with Tag7. PBMCs were incubated with Tag7 for 22 and $46 \mathrm{~h}$, and the $\mathrm{CD}^{+} \mathrm{CD}^{+}$subpopulation was then isolated by magnetic separation to evaluate changes in the levels 
of mRNAs from the above genes. After $22 \mathrm{~h}$ incubation, the mRNA levels for IL-2 and CD25 receptor subunit were enhanced most strongly (more than 130-fold), while enhancement in the mRNA levels for other receptor subunits and IFN $\gamma$ was an order of magnitude lower, with a similar pattern being observed after $46 \mathrm{~h}$ (Figure $3 \mathrm{c}$ ). Thus, $\mathrm{CD}^{+} \mathrm{CD}^{+}$cells from the Tag-7-treated PBMC pool showed an enhanced gene expression for cytokines IL-2 and IFN $\gamma$, which stimulate lymphocyte activation, and for IL-2 receptor subunits (especially CD25), which improve IL-2 signal transmission, such that CD25 (IL-2R $\alpha$ ) ensures high affinity of IL-2 binding.

These results confirm that IL-2 produced by $\mathrm{CD}^{+} \mathrm{CD}^{+}$cells plays a key role in inducing the cytotoxic activity of lymphocytes: if these cells are removed from the Tag7-PBMC system, IL-2 is absent in the conditioned medium, and active cytotoxic lymphocytes are not generated.

\subsection{Role of IL-2 Receptor in the Induction of Cytotoxic Lymphocytes}

Cells expressing individual IL-2R subunits were removed from PBMCs by magnetic separation, and the remaining cells were treated with Tag7 and tested for cytotoxic activity. As shown in Figure 4a, no cytotoxicity was observed after the removal of cells expressing IL-2R $\alpha$ (CD25) or IL-2R $\gamma$ (CD132) subunits, whereas the removal of IL-2R $\beta$ (CD122)-positive cells did not prevent the induction of cytotoxic lymphocytes. Therefore, two IL-2 receptor subunits, CD25 and CD132, are necessary for the formation of cytotoxic lymphocyte subpopulations.

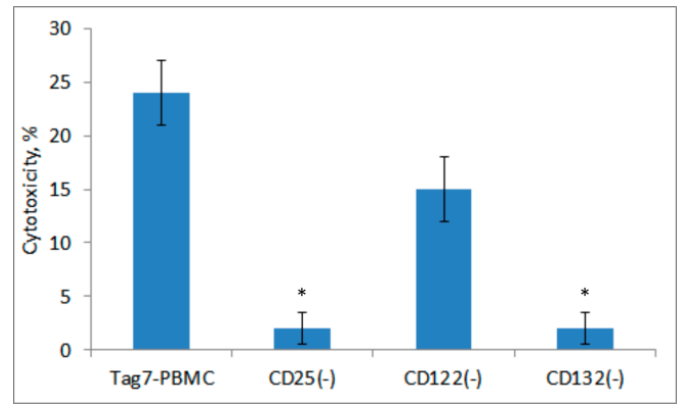

(a)

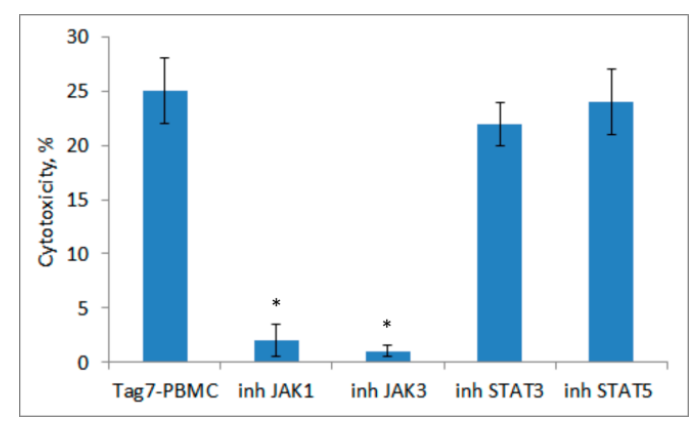

(b)

Figure 4. Role of IL-2 receptor in activating signal transmission. (a) Lymphocytes expressing IL-2R $\alpha$ (CD25), IL-2R $\beta$ (CD122) and IL-2R $\gamma$ (CD132) subunits were removed from PBMCs by magnetic separation, and the remaining cells were incubated with Tag7 for 6 days and tested for cytotoxicity against K562 cells. (b) JAK-STAT pathway is involved in PBMC activation by Tag7. PBMCs were incubated with Tag7 for 6 days in the presence of specific inhibitors of JAK1, JAK3, STAT3 and STAT5 (added $1 \mathrm{~h}$ before treatment and additionally added on days 3 and 5 in the case of STAT3 and STAT5) and tested for cytotoxicity against K562 cells. PBMCs after 6 days incubation with Tag7 tested for control cytotoxicity. Data are presented as the mean \pm SD of 3 independent experiments. Differences from the control in all cases are significant at * $p<0.05$ (2-way ANOVA).

Cytokine IL-2 secreted to the medium during PBMC incubation with Tag7 is the main factor responsible for activation of cytotoxic lymphocyte subpopulations. Therefore, it was relevant to estimate what stages of signal transduction from the IL-2 receptor are indispensable for the induction of lymphocyte cytotoxicity. It is known that cytoplasmic kinases JAK1 иJAK3 are functionally coupled to the IL-2 receptor and required for signal transduction [19]. To block their activity, we used specific JAK1 and JAK3 inhibitors, which were added to PBMCs $1 \mathrm{~h}$ before their treatment with Tag7. No cytotoxic effect was observed after 6 days of incubation with each of the inhibitors (Figure $4 b$ ), indicating that the induction of cytotoxicity depends on activation of JAK1 and JAK3 kinases upon IL-2 binding to the receptor. These kinases, in turn, activate STAT3 and STAT5 proteins, which are translocated as dimers into the nucleus and initiate gene transcription [20,21]. The role of this process in signal transduction was evaluated using STAT3 and STAT5 inhibitors that block their dimerization. The experimental procedure was the same as above, but the results showed that treatment with these inhibitors did not 
affect the induction of cytotoxic lymphocytes. Therefore, the IL-2-JAK signaling pathway does not depend on dimerization of STAT3 and STAT5 transcription factors.

\section{Discussion}

Here, we have described the basic stages of signal transmission from Tag7 to effector lymphocytes and identified the factors responsible for the induction of cytotoxic lymphocyte subpopulations capable of killing immune-evasive tumor cells.

The induction of such subpopulations under the effect of Tag7 depends on the consecutive activation of monocytes and $\mathrm{CD}^{+}{ }^{+} \mathrm{CD}^{+}$-lymphocytes. Tag7 binding to the TREM- 1 receptor on the surfaces of monocytes stimulates the production of not only proinflammatory cytokine TNF $\alpha$ but also of IFN $\gamma$, which has been shown for the first time. We have shown that treating $\mathrm{CD}^{+} \mathrm{CD}^{+}$-lymphocytes with TNF $\alpha$ and IFN $\gamma$ leads to the expression of mRNA of activating cytokines IL-2 and IFN $\gamma$. Thus, the cytokines secreted by monocytes transmit the activation signal to $\mathrm{CD} 3^{+} \mathrm{CD} 4^{+}$-lymphocytes, which in turn play a central role in its transmission to effector lymphocyte subpopulations.

Cytokine IL-2 is the main factor of T lymphocyte development [22]. Tag7-activated $\mathrm{CD}^{+} \mathrm{CD}^{+}$ lymphocytes are the main source of IL-2, which is necessary for the maturation of each subpopulation of cytotoxic $\mathrm{CD} 16^{+} \mathrm{CD}_{6} 6^{+}, \mathrm{CD}^{+} \mathrm{CD}^{+}{ }^{+}$and $\mathrm{CD}^{+}{ }^{+} \mathrm{CD} 8^{+}$cells. The $\mathrm{CD} 16^{+} \mathrm{CD} 56^{+}$-lymphocytes are activated by day 4 of Tag7 treatment, and then these cells disappear within a very short time [7]. We detected cytotoxic activity of $\mathrm{CD}^{+} \mathrm{CD}^{+}$-lymphocytes on the 4th and 6th days of incubation of PBMC with Tag7 and its absence on the 5th day. We suppose that on the 4 th and $6^{\text {th }}$ days the cytotoxic activity of $\mathrm{CD}^{+} \mathrm{CD}^{+}$-lymphocytes was caused by different subpopulations of $\mathrm{CD}^{+} \mathrm{CD} 4^{+}$-lymphocytes, while the $\mathrm{CD}^{+} \mathrm{CD}^{+}$lymphocyte population becomes active only by the 6th day of incubation PBMC with Tag7. It is possible that the maturation of $\mathrm{CD}^{+} \mathrm{CD}^{+}$-lymphocytes depends on the level of IL-2 cytokine, which continuously increases over 6 days.

IL-2 cytokine induces noncanonical cytotoxic T cell subpopulations that produce a nonspecific immune response against MHC-negative tumor cells [6]. We have shown here that the level of IL-2 in the medium conditioned by Tag7-treated PBMCs consistently increased during the 6-day incubation period. This may be explained by changes in gene expression in $\mathrm{CD}^{+}$lymphocytes that lead to enhanced mRNA synthesis for IL-2 and the subunits of its receptor. The expression of these subunits on $\mathrm{CD}^{+}$lymphocytes provides higher affinity of IL-2 binding and additional autostimulation of $\mathrm{CD}^{+} \mathrm{CD}^{+}$-lymphocytes. The gene coding for IFN $\gamma$ is also activated in $\mathrm{CD}^{+} \mathrm{CD}^{+}$-lymphocytes. This factor apparently acts synergistically with IL-2 and contributes to lymphocyte activation.

The receptor for IL-2 on the cell surface consists of three subunits: IL-2R $\alpha$ (CD25), IL-2R $\beta$ (CD122) and IL-2R $\gamma$ (CD132) [22]. All of them are necessary for high-affinity binding of this cytokine. Our results show that at least two subunits-IL-2R $\alpha$ and IL-2R $\gamma$ - should be expressed on the surface of lymphocytes to ensure IL-2 signal transmission and induction of cytotoxicity; i.e., they are sufficient for the assembly of a high-affinity receptor that allows lymphocytes to receive the activation signal.

The interaction of IL-2 with its receptor induces activation signal transduction via JAK1 and JAK3 tyrosine kinases associated with the $\beta$ and $\gamma$ subunits of the receptor, respectively [19]. Our results show that the induction of lymphocyte occurs via this signal transduction pathway, with the involvement of JAK1 and JAK3 kinases, but does not depend on dimerization of STAT3 and STAT5 transcription factors. It may well be that inhibitors used in this study prevent dimerization but do not interfere with the functional activity of these factors, since there is published evidence for the involvement of STAT proteins in signal transduction from the IL-2 receptor $[20,21]$.

Thus, a probable scheme of activation signal transmission from Tag7 to effector lymphocytes in PBMCs is as follows (Scheme 1). First, Tag7 binds to TREM-1 receptor on monocytes and thereby activates the genes of proinflammatory cytokines. Cytokines secreted in the early days, TNF $\alpha$ and IFN $\gamma$, influence $\mathrm{CD}^{+} \mathrm{CD}^{+}$lymphocytes. This stage is essential for the activation of $\mathrm{CD}^{+}$ $\mathrm{CD} 4^{+}$-lymphocytes, which play a central role in subsequent regulation. These lymphocytes are the source of IL-2, which is necessary for the maturation of cytotoxic subpopulations of NK cells 
and $\mathrm{CD}^{+} \mathrm{CD}^{+}$lymphocytes and also stimulates the cytotoxicity of the $\mathrm{CD} 3^{+} \mathrm{CD} 4^{+}$subpopulation. The efficiency of the signal received from IL-2 depends on the expression of all receptor subunits on the cell surface, which ensures the assembly of the cytokine-high-affinity-receptor complex and signal transduction in the cell.

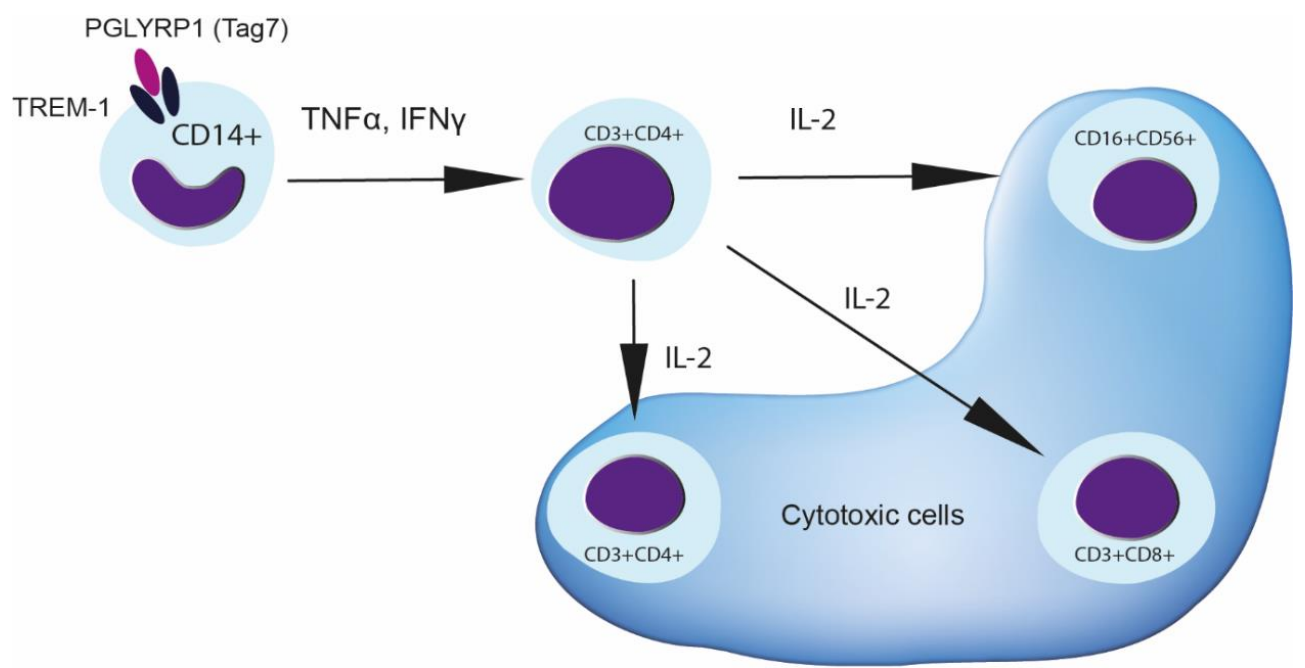

Scheme 1. Tag7 leads to the appearance of cytotoxic lymphocytes after incubation with PBMC. Once Tag7 binds to TREM-1 on monocytes, the cytokine production of TNF $\alpha$ and IFN $\gamma$ may be induced. This leads to the activation of $\mathrm{CD} 3^{+} \mathrm{CD} 4^{+}$lymphocytes to secrete IL-2 cytokine. Appearance of IL-2 in conditioned medium promotes the maturation of cytotoxic lymphocytes $\mathrm{CD} 3^{+} \mathrm{CD} 4^{+}, \mathrm{CD} 16^{+} \mathrm{CD} 56^{+}$ and $\mathrm{CD}^{+} \mathrm{CD}^{+}$.

Supplementary Materials: The following are available online at http://www.mdpi.com/2073-4409/9/12/2602/s1, Figure S1: Changes in cytotoxic activity of different lymphocyte subpopulations induced in PBMC incubated with Tag7 $\left(10^{-9} \mathrm{M}\right)$ for different periods of time. Figure S2: Secretion of IL-2 by CD3 ${ }^{+} \mathrm{CD} 4^{+}$lymphocytes incubated with TNF $\alpha$ or IFN $\gamma$ for 24 and $48 \mathrm{~h}$. CD $3^{+} \mathrm{CD}^{+}$-lymphocytes were isolated by magnetic cell separation from PBMC on day 0 and treated with TNF $\alpha$ or IFN $\gamma$. Figure S3: Cytotoxicity Tag7-PBMC in the presence of specific antibodies to $\mathrm{TNF} \alpha, \mathrm{IFN} \gamma$ and IL-2.

Author Contributions: Conceptualization, L.P.S., D.V.Y. and T.N.S., methodology, O.K.I.; software, D.V.Y.; validation, L.P.S. and D.V.Y.; formal analysis, L.P.S., D.V.Y. and T.N.S.; investigation, T.N.S., E.A.R. and O.K.I.; writing-original draft preparation, T.N.S. and L.P.S.; writing-review and editing L.P.S., D.V.Y. and T.N.S.; visualization, E.A.R.; supervision, L.P.S.; project administration, L.P.S.; funding acquisition, L.P.S. All authors have read and agreed to the published version of the manuscript.

Funding: This work was funded by a grant from the Ministry of Science and Higher Education Russian Federation (agreement No. 075-15-2020-773).

Conflicts of Interest: The authors declare no conflict of interest.

\section{References}

1. Kang, D.; Liu, G.; Lundström, A.; Gelius, E.; Steiner, H. A peptidoglycan recognition protein in innate immunity conserved from insects to humans. Proc. Natl. Acad. Sci. USA 1998, 95, 10078-10082. [CrossRef] [PubMed]

2. Cho, J.H.; Fraser, I.P.; Fukase, K.; Kusumoto, S.; Fujimoto, Y.; Stahl, G.L.; Ezekowitz, R.A.B. Human peptidoglycan recognition protein $S$ is an effector of neutrophil-mediated innate immunity. Blood 2005, 106, 2551-2558. [CrossRef] [PubMed]

3. Liu, C.; Xu, Z.; Gupta, D.; Dziarski, R. Peptidoglycan recognition proteins: A novel family of four human innate immunity pattern recognition molecules. J. Biol. Chem. 2001, 276, 34686-34694. [CrossRef] [PubMed]

4. Sashchenko, L.P.; Dukhanina, E.A.; Yashin, D.V.; Shatalov, Y.V.; Romanova, E.A.; Korobko, E.V.; Demin, A.V.; Lukyanova, T.I.; Kabanova, O.D.; Khaidukov, S.V.; et al. Peptidoglycan Recognition Protein Tag7 Forms a Cytotoxic Complex with Heat Shock Protein 70 in Solution and in Lymphocytes. J. Biol. Chem. 2004, 279, 2117-2124. [CrossRef] 
5. Yashin, D.V.; Ivanova, O.K.; Soshnikova, N.V.; Sheludchenkov, A.A.; Romanova, E.A.; Dukhanina, E.A.; Tonevitsky, A.G.; Gnuchev, N.V.; Gabibov, A.G.; Georgiev, G.P.; et al. Tag7 (PGLYRP1) in Complex with Hsp70 Induces Alternative Cytotoxic Processes in Tumor Cells via TNFR1 Receptor. J. Biol. Chem. 2015, 290, 21724-21731. [CrossRef]

6. Sashchenko, L.P.; Dukhanina, E.A.; Shatalov, Y.V.; Yashin, D.V.; Lukyanova, T.I.; Kabanova, O.D.; Romanova, E.A.; Khaidukov, S.V.; Galkin, A.V.; Gnuchev, N.V.; et al. Cytotoxic T lymphocytes carrying a pattern recognition protein Tag7 can detect evasive, HLA-negative but Hsp70-exposing tumor cells, thereby ensuring FasL/Fas-mediated contact killing. Blood 2007, 110, 1997-2004. [CrossRef]

7. Sharapova, T.N.; Ivanova, O.K.; Soshnikova, N.V.; Romanova, E.A.; Sashchenko, L.P.; Yashin, D.V. Innate Immunity Protein Tag7 Induces 3 Distinct Populations of Cytotoxic Cells That Use Different Mechanisms to Exhibit Their Antitumor Activity on Human Leukocyte Antigen-Deficient Cancer Cells. J. Innate Immun. 2017, 9, 598-608. [CrossRef]

8. Gibot, S.; Cravoisy, A.; Kolopp-Sarda, M.-N.; Béné, M.-C.; Faure, G.; Bollaert, P.-E.; Levy, B. Time-course of sTREM (soluble triggering receptor expressed on myeloid cells)-1, procalcitonin, and C-reactive protein plasma concentrations during sepsis. Crit. Care Med. 2005, 33, 792-796. [CrossRef]

9. Dower, K.; Ellis, D.K.; Saraf, K.; Jelinsky, S.A.; Lin, L.-L. Innate Immune Responses to TREM-1 Activation: Overlap, Divergence, and Positive and Negative Cross-Talk with Bacterial Lipopolysaccharide. J. Immunol. 2008, 180, 3520-3534. [CrossRef]

10. Chu, W.-M. Tumor necrosis factor. Cancer Lett. 2013, 328, 222-225. [CrossRef]

11. Yang, S.; Wang, J.; Brand, D.D.; Zheng, S.G. Role of TNF-TNF Receptor 2 Signal in Regulatory T Cells and Its Therapeutic Implications. Front. Immunol. 2018, 9, 784. [CrossRef]

12. Stetson, D.B.; Mohrs, M.; Reinhardt, R.L.; Baron, J.L.; Wang, Z.-E.; Gapin, L.; Kronenberg, M.; Locksley, R.M. Constitutive Cytokine mRNAs Mark Natural Killer (NK) and NK T Cells Poised for Rapid Effector Function. J. Exp. Med. 2003, 198, 1069-1076. [CrossRef]

13. Cote-Sierra, J.; Foucras, G.; Guo, L.; Chiodetti, L.; Young, H.A.; Hu-Li, J.; Zhu, J.; Paul, W.E. Interleukin 2 plays a central role in Th2 differentiation. Proc. Natl. Acad. Sci. USA 2004, 101, 3880-3885. [CrossRef]

14. Reem, G.H.; Yeh, N.H. Interleukin 2 regulates expression of its receptor and synthesis of gamma interferon by human T lymphocytes. Science 1984, 225, 429-430. [CrossRef]

15. Romanova, E.A.; Dukhanina, E.A.; Sharapova, T.N.; Sashchenko, L.P.; Gnuchev, N.V.; Yashin, D.V. Lymphocytes incubated in the presence of IL-2 lose the capacity for chemotaxis but acquire antitumor activity. Dokl. Biol. Sci. 2017, 472, 31-33. [CrossRef] [PubMed]

16. Read, C.B.; Kuijper, J.L.; Hjorth, S.A.; Heipel, M.D.; Tang, X.; Fleetwood, A.J.; Dantzler, J.L.; Grell, S.N.; Kastrup, J.; Wang, C.; et al. Cutting Edge: Identification of Neutrophil PGLYRP1 as a Ligand for TREM-1. J. Immunol. 2015, 194, 1417-1421. [CrossRef] [PubMed]

17. Burger, D.; Dayer, J.-M. The role of human T-lymphocyte-monocyte contact in inflammation and tissue destruction. Arthritis Res. 2002, 4 (Suppl. 3), S169-S176. [CrossRef] [PubMed]

18. Sojka, R.K.; Bruniquel, D.; Schwartz, R.H.; Singh, N.J. IL-2 Secretion by CD4 ${ }^{+}$T Cells In Vivo Is Rapid, Transient, and Influenced by TCR-Specific Competition. J. Immunol. 2004, 172, 6136-6143. [CrossRef]

19. Nelson, B.H.; Willerford, D.M. Biology of the Interleukin-2 Receptor. Adv. Immunol. 1998, 70, 1-81. [CrossRef]

20. Johnston, J.A.; Bacon, C.M.; Riedy, M.; O'Shea, J.J. Signaling by IL-2 and related cytokines: JAKs, STATs, and relationship to immunodeficiency. J. Leukoc. Biol. 1996, 60, 441-452. [CrossRef]

21. Taniguchi, T.; Miyazaki, T.; Minami, Y.; Kawahara, A.; Fujii, H.; Nakagawa, Y.; Hatakeyama, M.; Liu, Z.-J. IL-2 Signaling Involves Recruitment and Activation of Multiple Protein Tyrosine Kinases by the IL-2 Receptor. Ann. N. Y. Acad. Sci. 1995, 766, 235-244. [CrossRef] [PubMed]

22. Nelson, B.H. IL-2, Regulatory T Cells, and Tolerance. J. Immunol. 2004, 172, 3983-3988. [CrossRef] [PubMed]

Publisher's Note: MDPI stays neutral with regard to jurisdictional claims in published maps and institutional affiliations. 